\title{
Iberoamérica. ¿Nuevos modos de pensar y hacer arquitectura?
}

\author{
Ibero-America. New Ways of Thinking and Making Architecture?
}

$<$ Resumen>

El campo de acción y las condiciones que determinan la producción actual de arquitectura en lberoamérica son abordados por el siguiente artículo. Una arquitectura que se encierra influenciada por el heterogéneo paisaje sociocultural, económico y político que define a la región, la diversidad de países que la conforman.

$<$ Abstract>

The scope and conditions that determine the current production of architecture in lbero-America are addressed in this article. An architectural development related and influenced by the heterogeneous socio-cultural, economic and political landscape that defines the region and the different countries that compose it.

En el V centenario, Portugal y España habían consolidado sus democracias, y los países latinoamericanos habían abolido sus dictaduras militares, pero mientras a un lado del Atlántico se afianzaba la comunidad europea, América Latina padecía su primera década perdida. Hoy Europa sigue fantaseando con América, y ésta lleva 500 años reinventando al Viejo Continente.

Las continuas crisis económicas y políticas de América Latina se reflejan en la producción arquitectónica, ya que existe una clara interacción entre política y creatividad, economía y construcción de la ciudad.

Latinoamérica celebra en 2010 el bicentenario de su independencia, cada país lo celebrará a su manera y en un momento distinto. A finales de este año América Latina podría

<PALABRAS CLAVE>

IBEROAMÉRICA / EMERGENCIA / ARQUITECTURA CONTEMPORÁNEA / NUEVAS GENERACIONES

-KEYWOROS

IBERO-AMERICA / EMERGENCY / CONTEMPORARY ARCHITECTURE / NEW GENERAT IONS estar gobernada por un amplio espectro de partidos diferentes en sus políticas públicas Más que en la política económica o social, esa heterogeneidad se reflejará en las alianzas regionales que deciden las tensiones geopolíticas del hemisferio y en el trazado de fronteras ideológicas.

Hoy podemos afirmar que la región ha consolidado la democracia, sorteado la crisis económica mundial. Existen sutiles diferencias entre los términos: Latinoamérica, Hispanoamérica, e Iberoamérica, pero es importante entender que estamos frente a una designación cultural de significado históricamente variable. Iberoamérica no es un espacio natural, ni geográficamente continuo, sino esencialmente histórico y cultural, pero de gran envergadura.
Iberoamérica es una comunidad formada por los países de Europa y América Latina que hablan en español y portugués, un total de 22 estados con 600 millones de ciudadanos, compartiendo un tiempo histórico cuyas raíces comunes fortalecen la posibilidad de un sinfín de diferentes modos de habitar el mundo, formar parte de una comunidad transcontinental de tal riqueza es un privilegio. El ámbito de análisis es Iberoamérica, entendida como una situación que favorece oportunidades entre los arquitectos emergentes, generando vínculos, algunos existentes y otros posibles, entre profesionales individuales o colectivos, otros son de tipo académico, dibujando una red infinita, basada en la utilización de los nuevas estrategias de comunicación digitales, de la nueva arquitectura iberoamericana.

\footnotetext{
* Arquitecta por la ETSAM. Centra su actividad profesional en la difusión y comunicación de Urbanismo y Arquitectura. Es corresponsal en Madrid de diversas revistas nacionales e internacionales: A10, summa, ARQ, 2 G dossier, PISO Desde el año 2000 es comisaria del programa de investigación Panorama Emergente Iberoamericano, y desde 2006 es comisaria de la plataforma de difusión FRESHMADRID, desde 2009 FRESHLATINO, plataforma de difusión de arquitectura iberoamericana. En 2008 crea junto con Andrés Jaque la plataforma PIENSA MADRID, dentro de la programación de La Casa Encendida. Es experta nominator de los Premios Mies van der Rohe 2009, jurado de los Premios AEPD, antena invitada FAD city to city y miembro del comité científico del festival eme3. Ha participado en numerosas exposiciones, conferencias y seminarios en: Buenos Aires, Bruselas, Bogotá, Barcelona, São Paulo, Nueva York, Hamburgo, Frankfurt y Oporto entre otros. Actualmente divide su actividad entre la difusión de la arquitectura, la investigación y el comisariado, mediante proyectos, exposiciones y publicaciones, con el objetivo de generar un pensamiento crítico entre arquitectura y cultura contemporánea.
} 

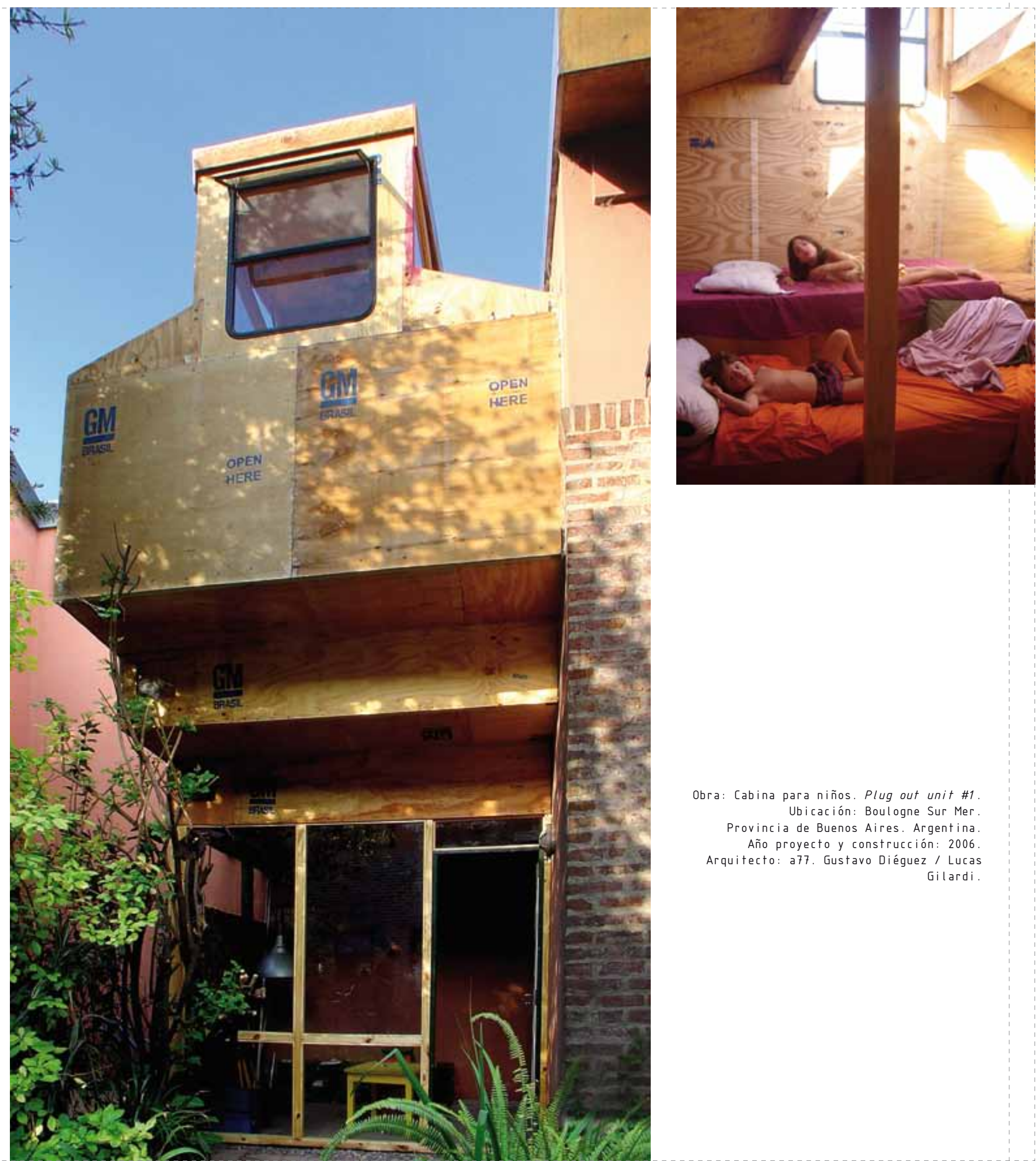

Obra: Cabina para niños. Plug out unit \#1. Ubicación: Boulogne Sur Mer. Provincia de Buenos Aires. Argentina. Año proyecto y construcción: 2006 Arquitecto: a 77. Gustavo Diéguez / Lucas Gilardi 
Sensible a la necesidad de apoyar a los jóvenes arquitectos iberoamericanos, inicié un programa de investigación desde una plataforma internacional de difusión permanente que intenta llegar a aquellos profesionales que ya sea por la escala de su trabajo o el bajo presupuesto que manejan se quedan una y otra vez fuera de los circuitos convencionales. Descubrir, entender y explicar el fenómeno de la arquitectura emergente iberoamericana resulta apasionante: la identificación de un grupo diverso, de naturaleza heterogénea que identifica sus similitudes en la interpretación de la cultura contemporánea. Comprender la producción de este grupo de jóvenes supone una lección singular en cuanto a formas de iniciar la práctica profesional: los jóvenes trabajan en forma individual, en parejas o en equipos formando colectivos de hasta doce personas. Consiguen acortar las distancias participando del mundo global a través de las nuevas tecnologías de comunicación, a la vez que aislados del acontecer en un entorno próximo. Una característica de la generación de arquitectos emergentes es que rechaza toda forma de clasificación, sin embargo podemos distinguir la producción por países tipo: por un lado arquitectos que trabajan en minúsculas construcciones, otros transitan la transgresión entre arte y arquitectura, en los límites de la disciplina, o aquellos que proponen una nueva forma de acercarse a la ciudad.

\section{Países «tipo»}

Podemos hablar de países «tipo» según la realidad socioeconómica que atraviesan; países tipo Chile-México, donde la buena situación económica brinda oportunidades a los más jóvenes y existen numerosas publicaciones de calidad y la posibilidad de llegar al encargo a través de concursos. La cultura arquitectónica chilena presenta uno de los panoramas emergentes más interesantes de Iberoamérica, con numerosas escuelas de arquitectura de prestigio internacional.

Brasil es un caso excepcional, por su gran tamaño, y enorme dificultad, un panorama complejo, que no se va a entender hasta que las diferencias estén aceptadas y claras. Las nuevas generaciones siguen aún muy de cerca a sus maestros, aún vivos, quienes forman parte de los jurados de todos los concursos. Existe una gran dificultad para acceder a la información, las escuelas se diseminan por el país de forma disgregada y se basan en la enseñanza masiva, tienen un proyecto estético de bases consolidadas pero que camina de la mano del asilamiento geográfico, lo que puede explicar una cierta autosuficiencia de códigos estéticos y temas de debate que componen el discurso disciplinar. Según Ruth Verde «La arquitectura moderna en Brasil es un mito. La arquitectura contemporánea en Brasil un misterio. Qué pasó después de Brasilia? Esta es una pregunta latente de la que nadie habla o escribe.... ${ }^{1}$.

En los casos de Ecuador, Bolivia o Paraguay, países con problemas económicos y sociales, donde es casi imposible tener un trabajo, la posibilidad del encargo o del concurso queda relegada a unos pocos, presentando un escenario cultural indisciplinado, dramático y atractivo, donde todo es inestable y mutable, contradictorio y extremo, la arquitectura tiene expresiones insospechadas, llegando a la inexistencia del proyecto o del arquitecto. En tales escenarios la arquitectura se reduce a la simple construcción dirigida y ejecutada con grandes deficiencias materiales, tecnológicas o profesionales, los arquitectos son sobrevivientes ante realidades insólitas en un medio extremo. Se trabaja con la improvisación y la ilegalidad, la impunidad y el anonimato, la informalidad y la imprecisión, la irregularidad y la descoordinación, la falta de sentido común o de previsión.

El caso de Argentina, adopta modelos que ya funcionaron en Europa o los EE.UU., años más tarde, a veces décadas, el mercado es muy conservador y los arquitectos locales no se arriesgan, existen muy pocos concursos interesantes y ningún apoyo a la innovación e investigación. Las condiciones de extrema violencia en Colombia han generado una de las generaciones más creativas de Iberoamérica, desarrollando encargos del sector público y especialmente es en Medellín donde surge una comunidad de arquitectos cuyas propuestas llenas de sensibilidad son una verdadera lección, despegando gracias a políticas de estrategias urbanas de sus visionarios políticos.

Entre las nuevas generaciones el arquitecto estrella deja sitio al profesional en la calle mas próximo a la sociedad, investigador y experimental. La novedad entre estos arquitectos se identifica en la incorporación al repertorio de herramientas que provienen de la sociología, la política, la antropología, la economía, la ecología y que amplían y trascienden los límites de la multidisciplinariedad profesional planteados en la agenda moderna de arquitectos iberoamericanos; para ellos, la arquitectura ya no son objetos sino sistemas de trabajo. Sus temas son: bajo presupuesto, necesidades básicas, preocupaciones políticas y sociales, movilidad, temporalidad, subversión conceptual. Transitan una gran gama de posibilidades: desde interiores temporales o proyectos de pequeña escala, desde la instalación a la ejecución. Muchos de ellos tienen verificación física, generan experiencias inmediatas, hacen emerger un nuevo patrón de realidades, actúan en la frontera disciplinar, cruzándose con el diseño de moda, de mobiliario, la acción urbana, o la instalación.

Son infinitos los talleres, workshops, encuentros, seminarios instaurados dentro o al margen del paraguas académico, llegando a constituir una auténtica academia paralela. Otro fenómeno es el boom editorial, las exposiciones, y el uso de las herramientas multimedia en una generación que se comunica por skype, twitter o sms de forma constante, sustentado en un afán por difundir, comunicar y compartir

La sostenibilidad pasa a ser motivo de estudio redefiniendo lo verde, y también una necesidad: trabajar con lo existente, trabajar con lo encontrado, en este sentido son numerosos los equipos trabajando con residuos, reciclando o creando básicamente con basura. Los jóvenes arquitectos se aproximan a la ciudad y a la investigación del territorio de una forma diferente, manejan nuevas estrategias de interacción, y exploran la periferia de las ciudades documentándola, segregándola en partes, analizándola, describiéndola, desvelando sus patrones culturales, sociales, físicos y económicos.

Los jóvenes han sido protagonistas de un crecimiento urbano muchas veces informal, produciendo diferentes modos de estudiarlo. Desde aquí se puede estructurar una red de intercambio de información y cooperación para el desarrollo de propuestas alternas enfocadas al entendimiento y la proyección del territorio latinoamericano, España y Portugal, fundamentadas en la utilización estratégica de las nuevas tecnologías, la exploración de sistemas emergentes frente a la biodiversidad y la sostenibilidad, y la construcción de un pensamiento transversal que busca materializar la identidad iberoamericana contemporánea.

Si aceptamos que América fue el laboratorio del Movimiento Moderno de forma desigual y fragmentada, con episodios estelares, ¿Cuál es el papel de Iberoamérica hoy en el panorama de la arquitectura emergente y el pensamiento contemporáneo? 


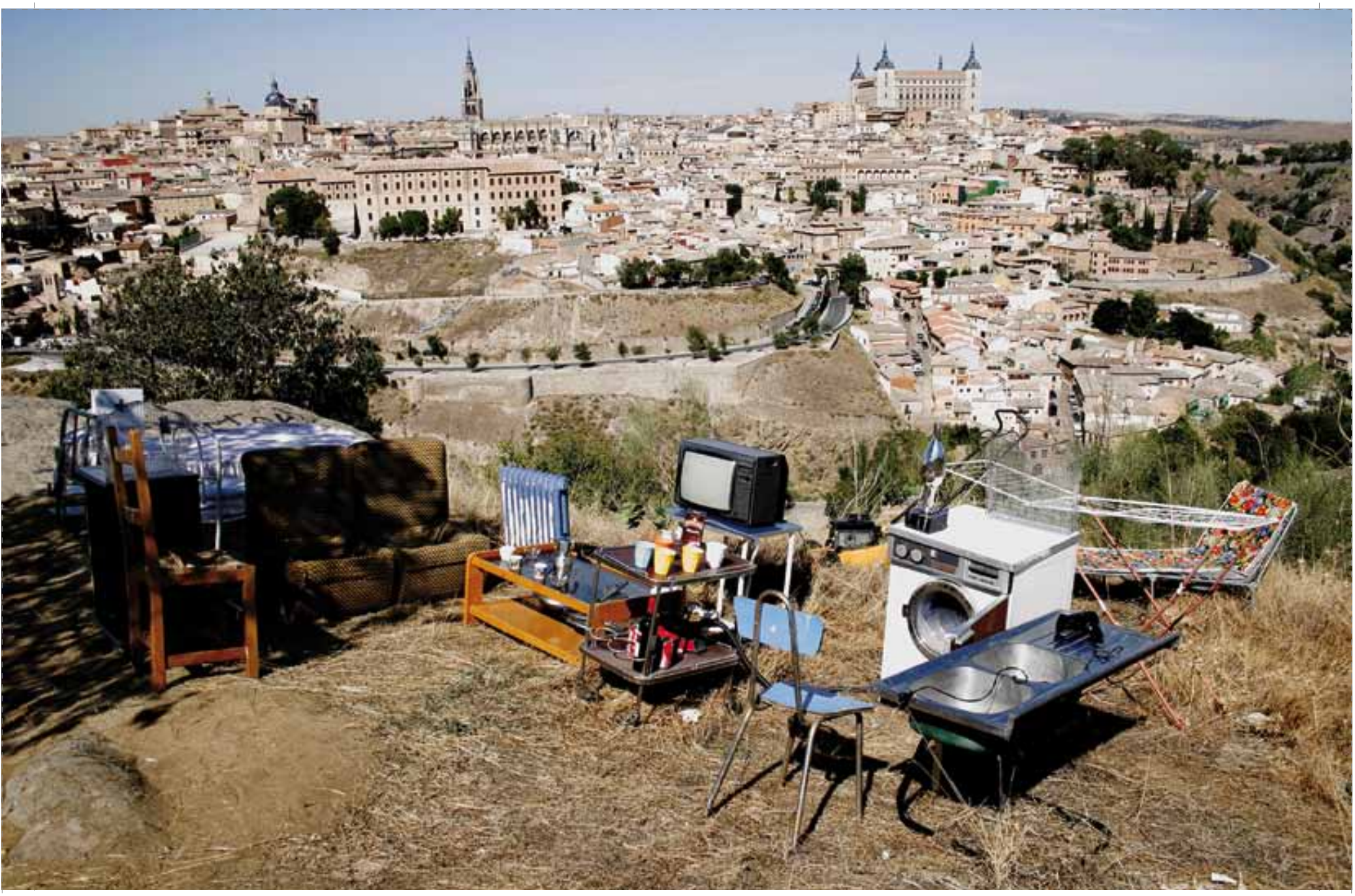

Obra: Toledo crea Toledo. Emplazamiento: Sala ECAT. Toledo, España. Año acción: 20/30 septiembre 2007 Coordinador: PKMN Sitio web: Www.toledocreatoledo.blogspot.com Fotos: PKMN

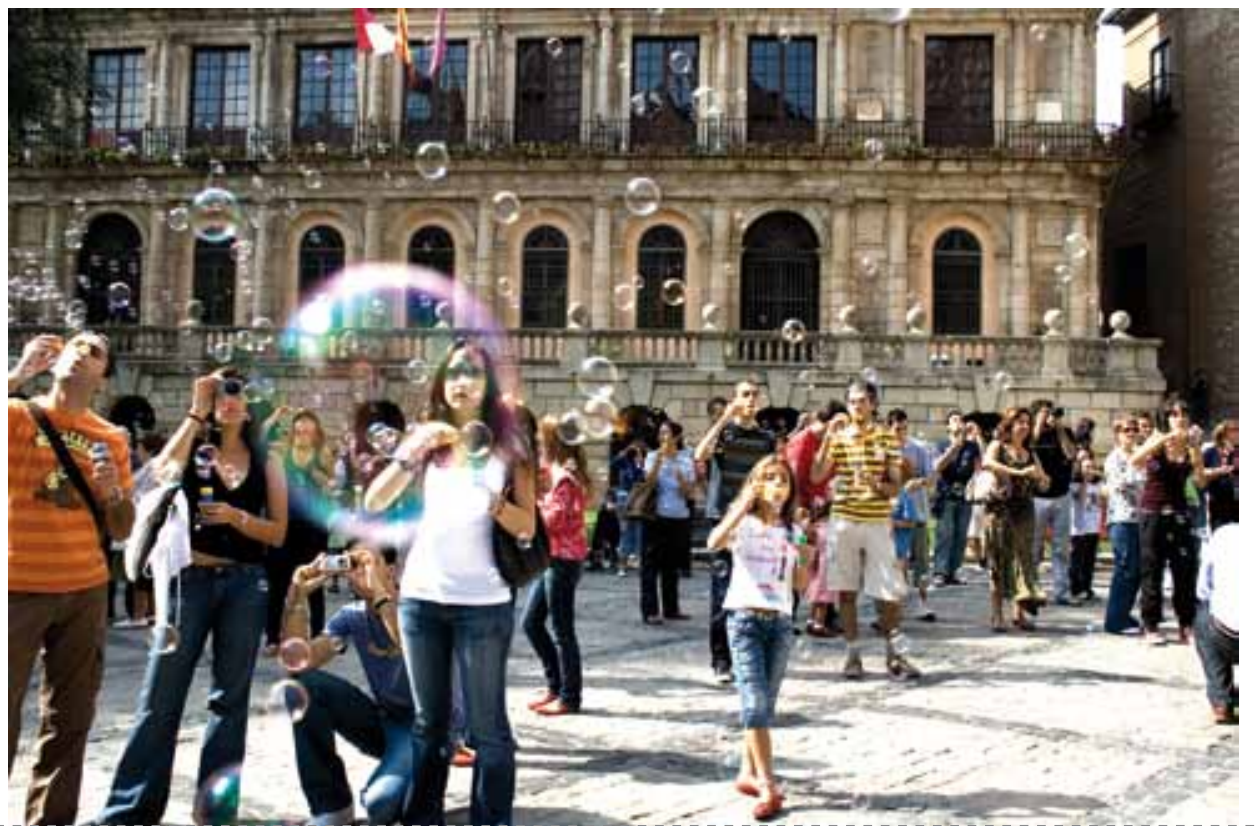




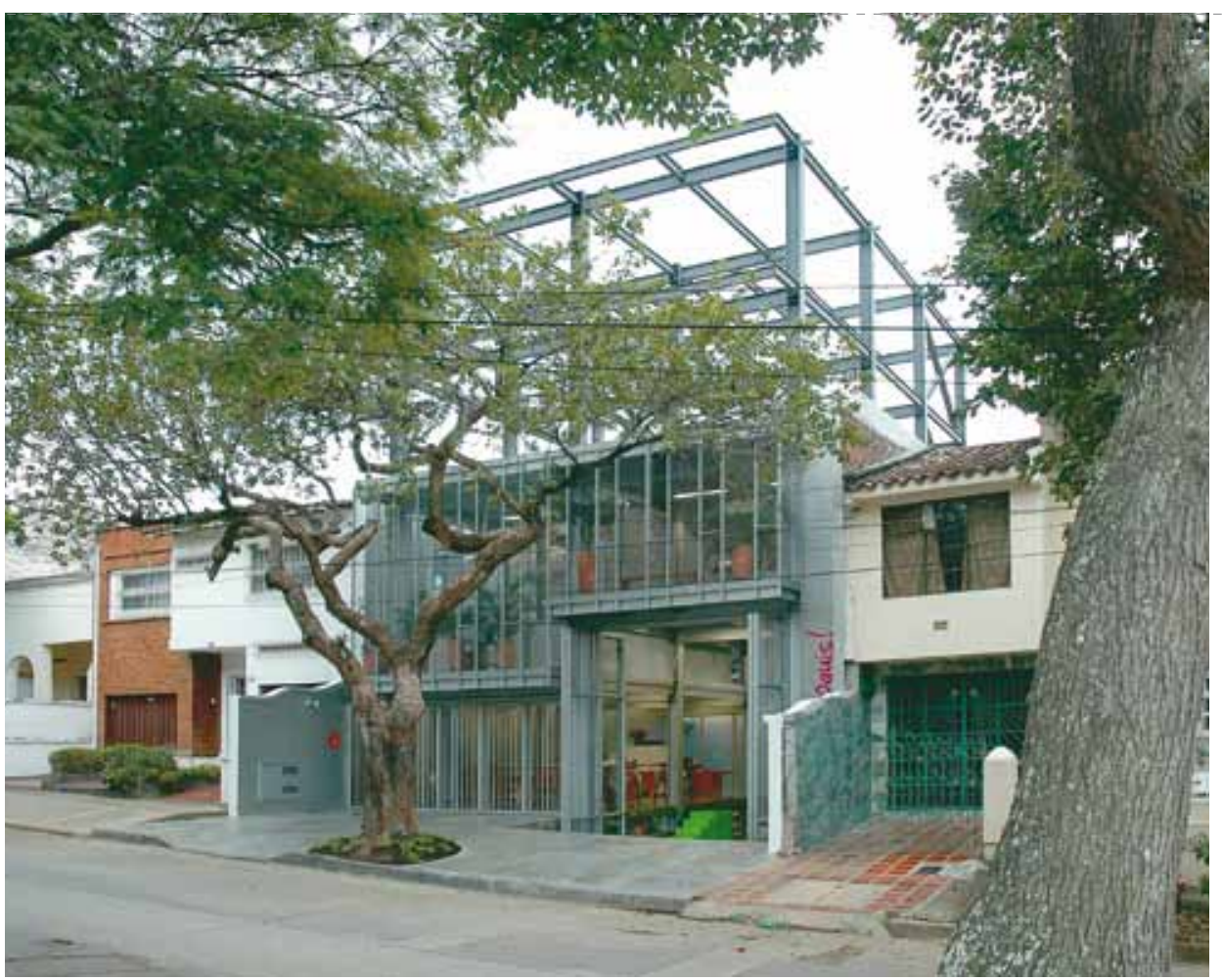

Obra.Casa-Taller Croquis. Edificio Jardín Hospedero y Nectarífero para Mariposas de Cali

Emplazamiento: Cali, Colombia.

Año construcción: 2006

Superficie: $510 \mathrm{~m}^{2}$

Arquitectos: Husos: Camilo García / Diego Barajas.

Biólogo: Francisco Amaro.

Colaboradores: Juan Pablo Arias; Antonio

Cobo; Junko Watanabe.

Construcción: Luis A Ramírez, arquitecto.

Estructura metálica: Jorge Mejía, ingeniero

Edición video de telenovelas: Osmandy

Fuentes, músico.

Fotografía: Javier García, Manuel Salinas y Sylvia Patiño.

Agradecimientos: Fundación Zoológico de Cali, Douglas Laing (Ingeniero Agrónomo especialista en agricultura tropicall. Lorena Ramírez (Bióloga. Universidad del Valle. Colombia), Luis M. Constantino (Biólogo Entomólogo, Ms.C, Investigador Asociado Centro Nacional de Investigaciones de Café. Cenicafé. Chinchinál. Ricardo A. Claro (Biólogo Entomólogo. Universidad Nacional de Colombia. Colombial, José Martín Cano (Biólogo Entomólogo. Universidad Autónoma de Madridl. María García, Manuel Salinas y Julián Velásquez.

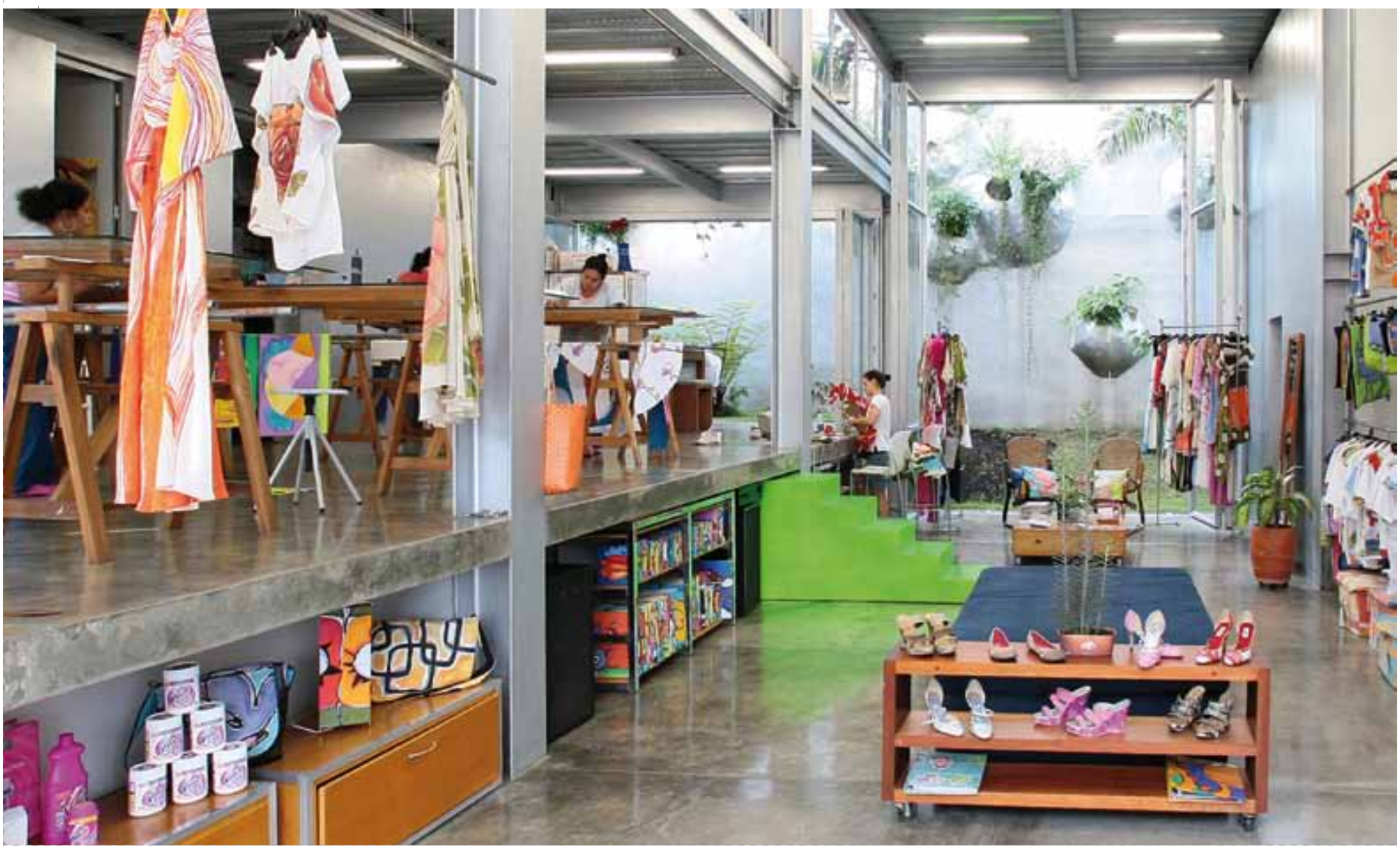




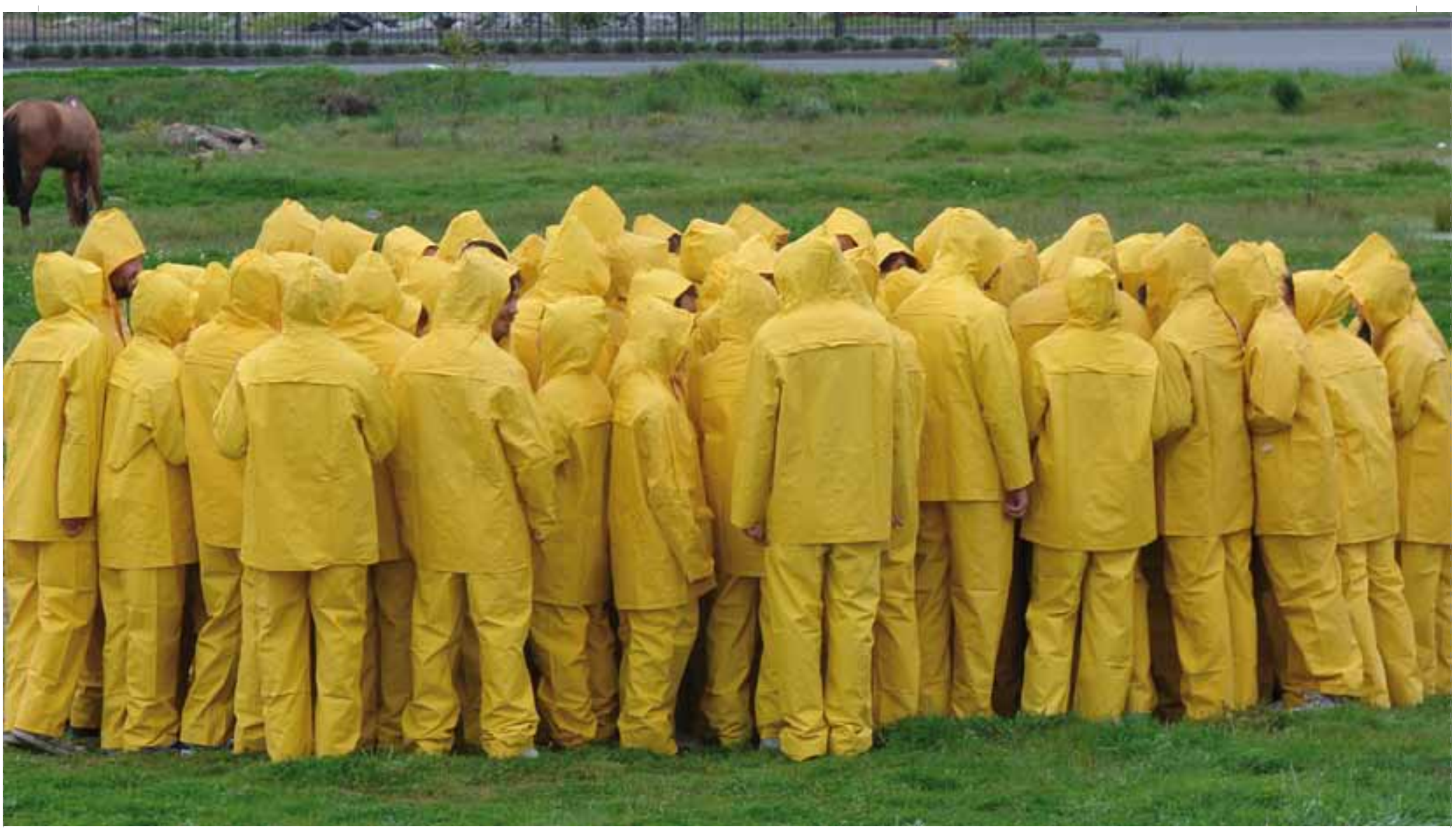

Obra: Temporal; velocidades de la

intemperie. Fecha: Sábado 30 septiembre 2006.

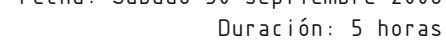
Autor: Mauricio Pezo
Producción: Pezo von Ellrichshausen Arquitectos Coordinadores: Sofía von Ellrichshausen: María Paz Palma: Andrés Moreno: Francisco Bretón; Ernesto Torrijos. Colaboradores: David Arriagada, Isaías Pérez y Brian Arriagada.

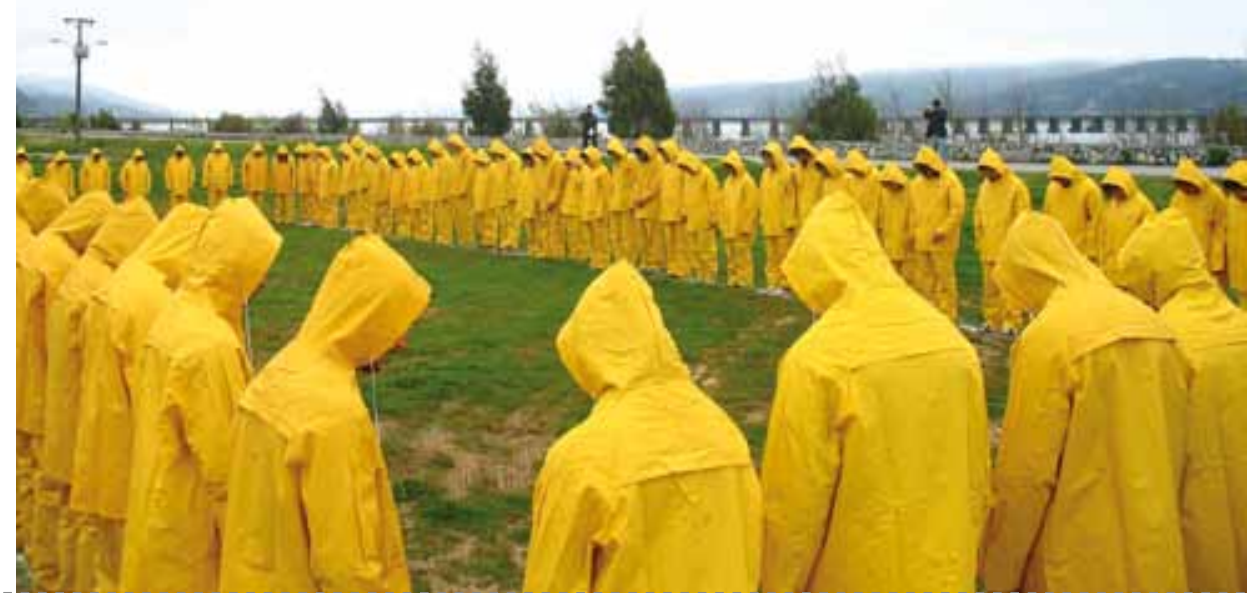



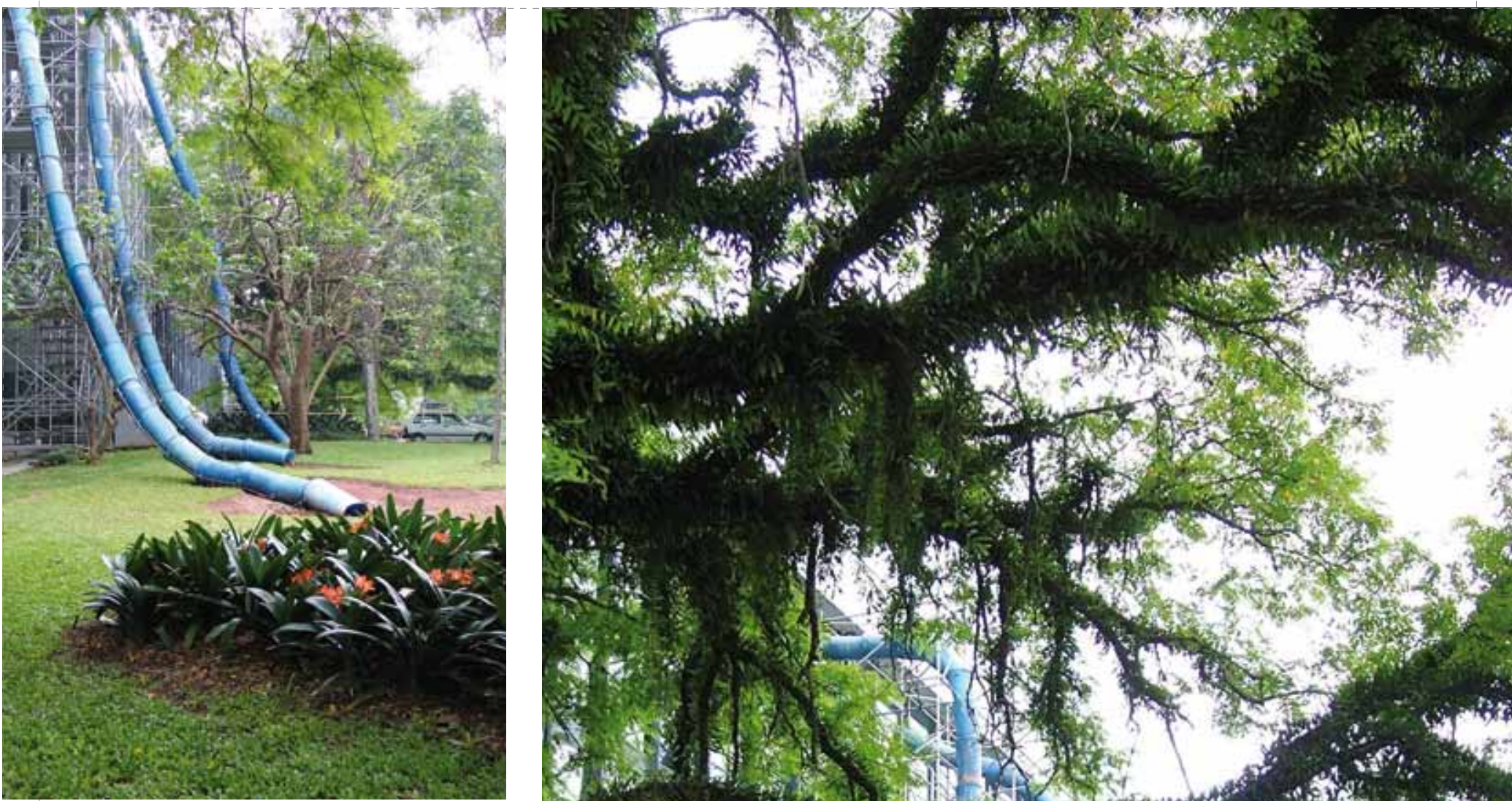

Obra: Entrada de Emergencia.

Ohra

Año proyecto y construcción: 2005.

Arquitecto: Pedro Bandeira.

Colaborador: Dulcinea Neves dos Santos.

Organización y Producción: Instituto das

Artes. Ministério da Cultura de Portugal.

Fotografía: Dulcinea Neves dos Santos y Pedro Bandeira.

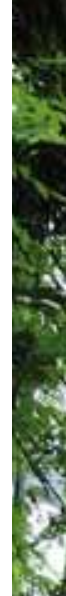

祍

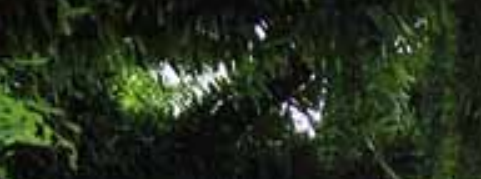

ints

a.

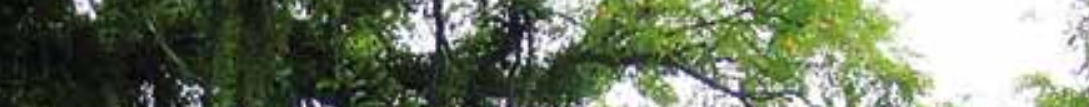

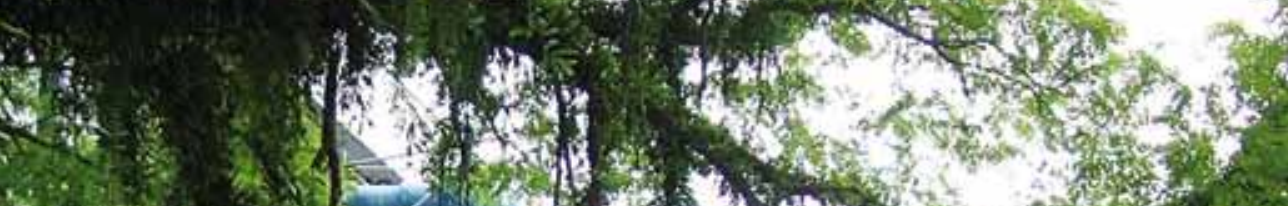

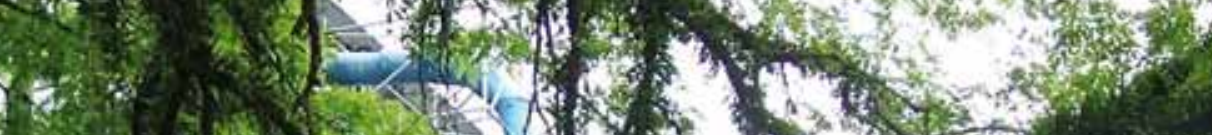

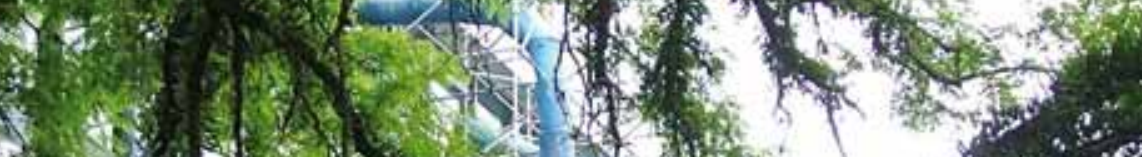

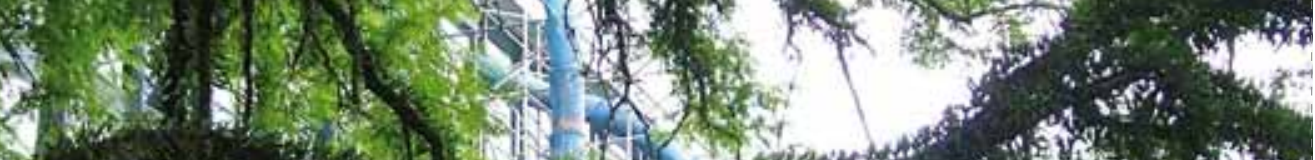

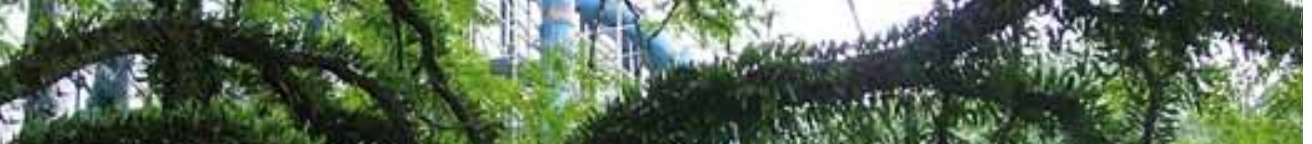

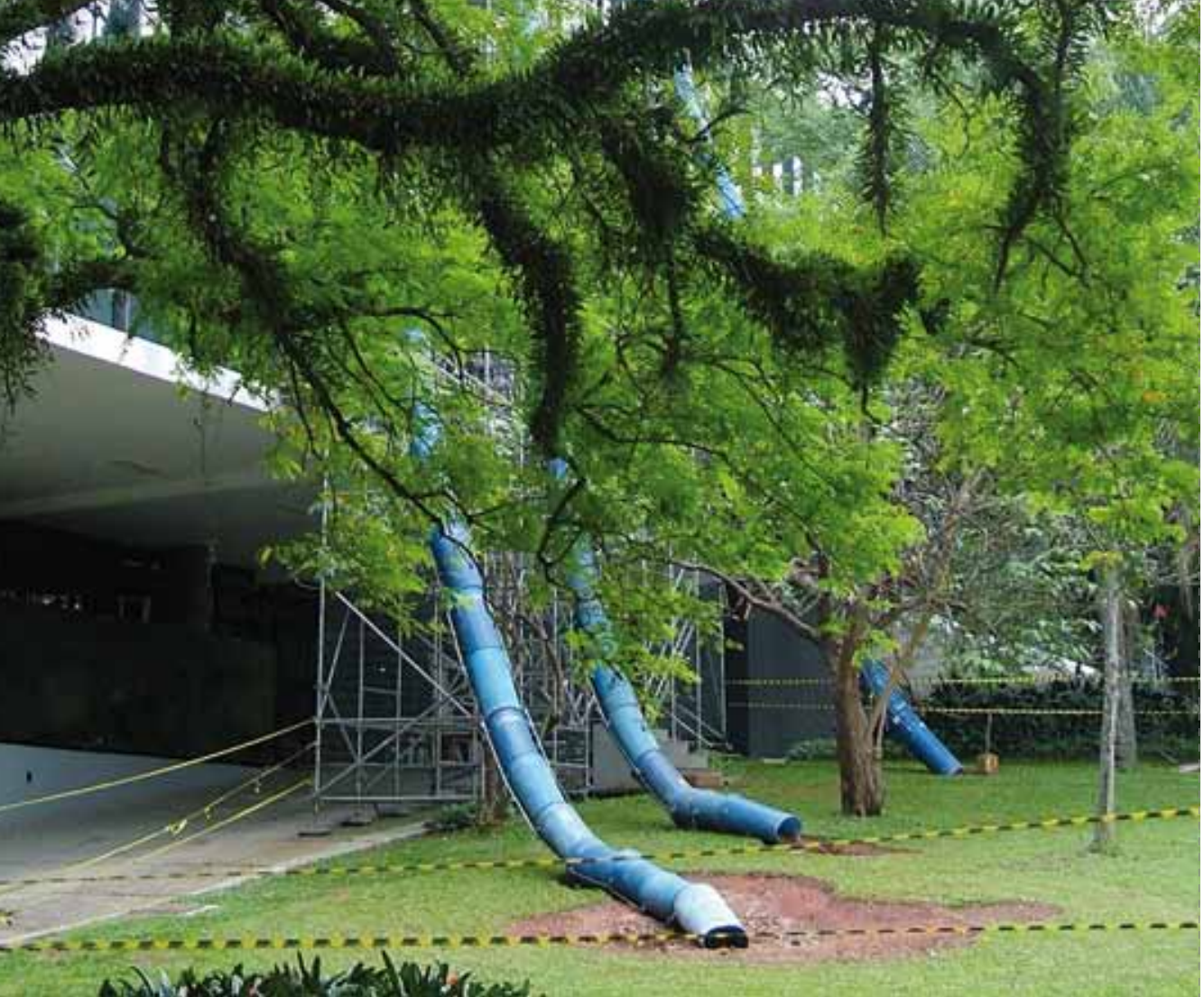




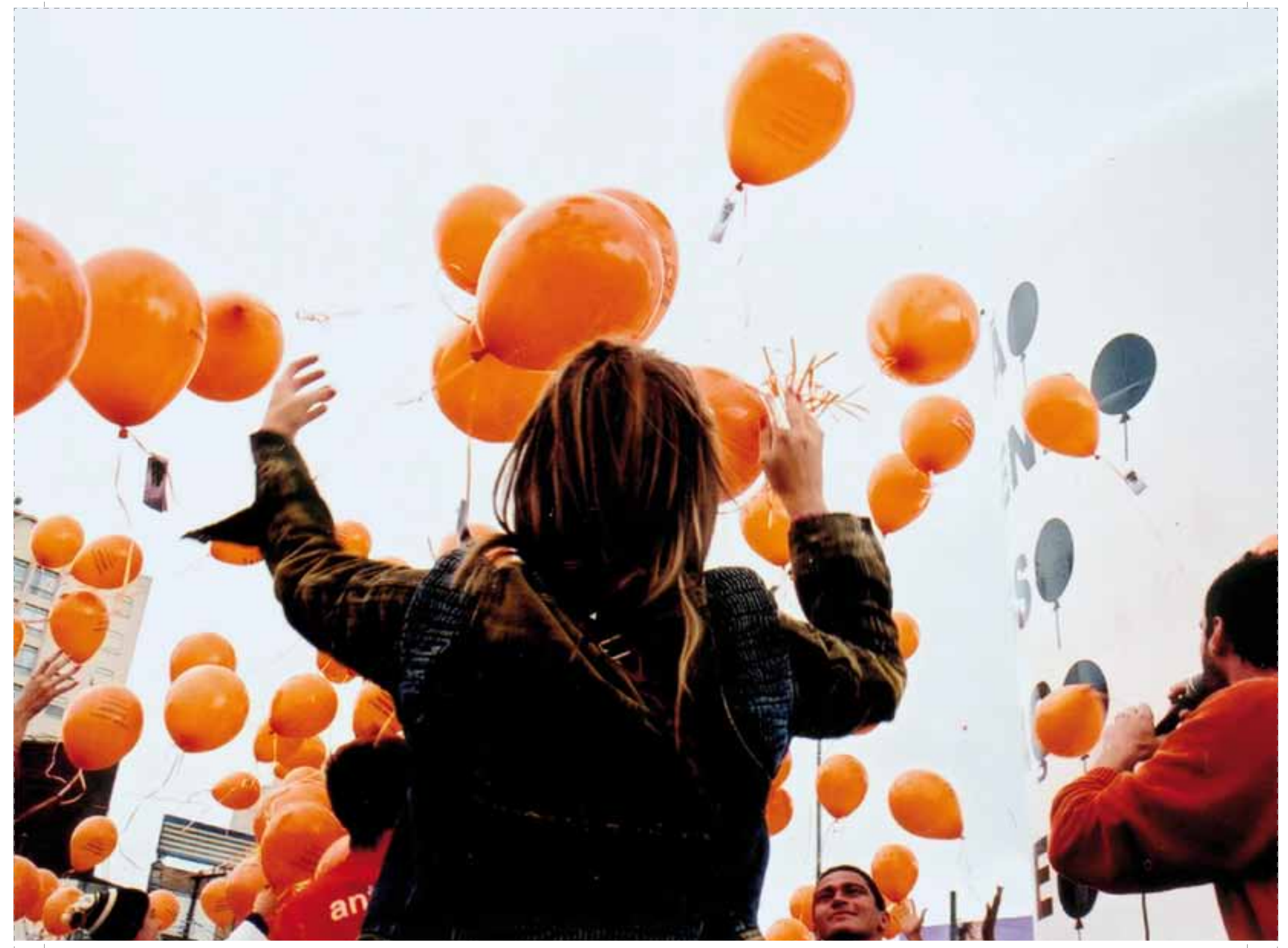

Obra:Zona de Acão. Emplazamiento: Sesc Paulista, São Paulo. Año proyecto: 2004 Fotos: Eduardo Merege y Peetsa.

Las imágenes publicadas pertenecen al «Proyecto Freshlatino» y la web: http://cve cervantes es/artes/freshlatino/

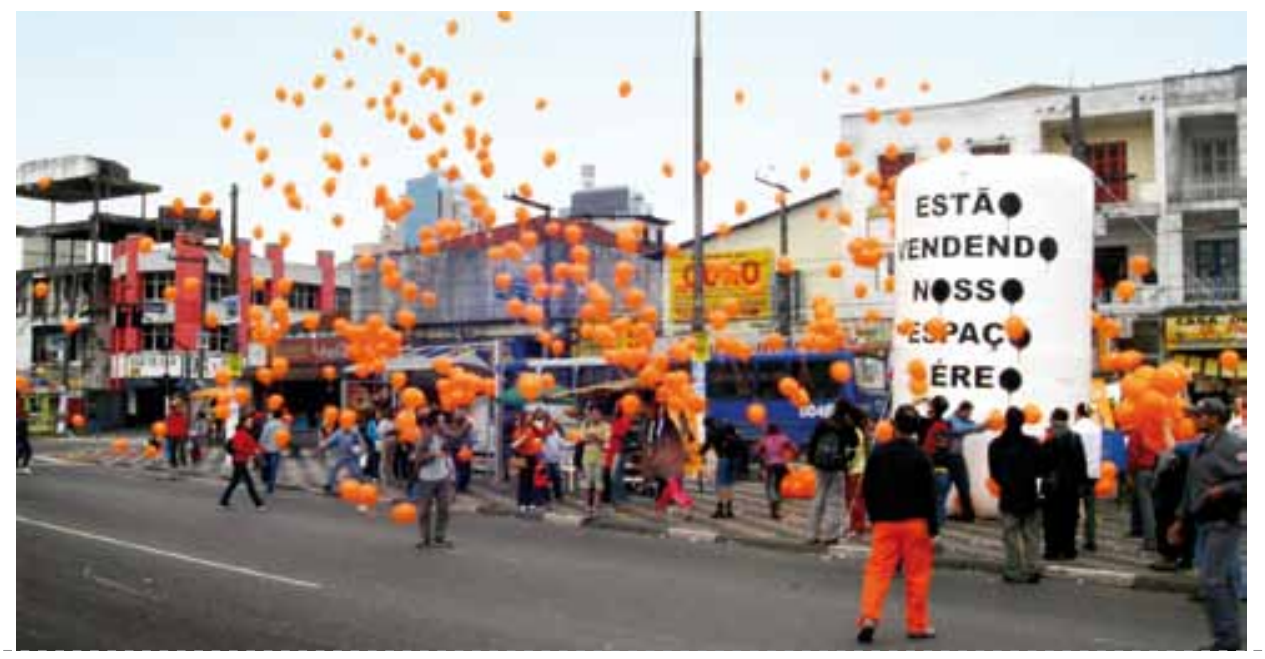

